\title{
A herança do olhar: de Charles Baudelaire a João do Rio, poeta e repórter documentam as ruínas da modernidade ${ }^{1}$
}

\section{Gustavo Zeitel}

Pontifícia Universidade Católica do Rio de Janeiro - PUC-Rio

Departamento de Comunicação Social - Bacharelado em Jornalismo

\begin{abstract}
Resumo
Sustentada pela Revolução Industrial, a modernidade alterou as relações sociais com o surgimento das metrópoles europeias. No presente estudo, demonstramos, a partir de uma revisão bibliográfica, que o poeta francês Charles Baudelaire concebeu a modernidade, alterando o estatuto da poesia lírica, adotando as transfigurações de dândi e "flâneur" na vacuidade da figura do herói romântico. O autor de "As flores do mal"construiu seu projeto poético no âmago da maré humana, deflagrando uma permanente zona de tensão entre eu "versus" multidão. A Proclamação da República no Brasil esforçou-se para fazer do Rio de Janeiro, a então capital, imagem e semelhança de Paris. Na belle époque, o cronista e repórter João do Rio adotou as mesmas transfigurações baudelairianas, tendo sido pioneiro no exercício da reportagem moderna.
\end{abstract}

Palavras-chave: modernidade; jornalismo; literatura; Baudelaire; João do Rio.

\section{Introdução}

O nascimento da modernidade foi sustentado pela Revolução Industrial, fenômeno responsável por alterar as relações sociais, com a emergência do capitalismo e a formação de grandes conglomerados urbanos. Respeitando o tempo útil do trabalho, as multidões materializaram o crescimento demográfico exponencial das principais metrópoles europeias. No presente trabalho, partiremos dos estudos críticos de Walter Benjamin sobre o poeta francês Charles Baudelaire, para compreendermos de que forma a modernidade alterou criação e recepção literárias, modificando o estatuto da poesia lírica. Em seguida, propõe-se uma análise comparativa entre as obras do poeta Charles Baudelaire e do cronista João do Rio, pioneiro no exercício da reportagem moderna.

\footnotetext{
${ }^{1}$ Artigo derivado de monografia de graduação em Jornalismo, orientada pela professora Rosamary Esquenazi, entregue em junho de 2021.
} 
Primeiramente, demonstra-se que o declínio da cidade medieval em detrimento da metrópole foi o reflexo inicial do mundo moderno. Ainda que a Revolução Industrial tenha transmitido uma idealização progressista, a vida em Paris era difícil para boa parte da população, que se adensava em vielas insalubres e mal iluminadas. Para a história francesa, o século XIX representou um período de tormenta política, com as Revoluções de 1830 e 1848 . Em paralelo, foi projetado um novo modelo para a capital francesa, que anos depois ganharia a alcunha de Cidade-luz.

No ensaio "A metrópole e a vida mental" (1903), o sociólogo alemão Georg Simmel identificou o cotidiano de choques e reações instintivas das grandes cidades, que seria traduzido na poesia moderna com a obra de Baudelaire. A publicação de "As flores do mal" substituiu a aura lírica da poesia romântica pela emergência do eu lírico que, como um esgrimista, encarou a vida moderna. O eu lírico baudelairiano "des-realizava" a cidade de Paris em "brumas" e "espectros", ao mesmo tempo que introduzia, na poesia, palavras como "candeeiro" e "lixeira", próprias do campo lexical da vida urbana, até então ignoradas pelos românticos.

O projeto poético baudelairiano arquitetou-se na vacuidade da figura heroica, como observou Walter Benjamin em "A Paris do Segundo Império na obra de Baudelaire"(1938). Dessa forma, o herói moderno passou a apresentar transfigurações mundanas - "flâneur" e dândi, por exemplo -, que se associam à biografia do poeta decadentista, acometido pelo sentimento de "spleen". No embate eu "versus" multidão, o olhar atento de Baudelaire registra a efemeridade da vida moderna em fragmentos poéticos, embriagados pelas sensações dos paraísos artificiais.

Em seguida, propõe-se uma investigação sobre a chegada da modernidade no Brasil, deflagrada na belle époque, período de maior influência francesa no país. No início do século XX, a República fez-se sob o signo positivista - ordem e progresso -, incorporando ideais higienistas da Europa. Dessa forma, o presidente Rodrigues Alves e o prefeito Pereira Passos ambicionaram fazer do Rio de Janeiro uma "Paris Tropical", no período que ficou conhecido como "Bota-Abaixo".

Se, na França, Baudelaire apreendeu a modernidade com seu projeto poético, no Brasil, João do Rio documentou os paradoxos da República. Com o surgimento de novas tecnologias para a imprensa, os jornais mediaram a arena discursiva do Rio de Janeiro em transformação. Criador da reportagem moderna, João do Rio modernizou os gêneros jornalísticos da época, identificando a rua como campo etnográfico do repórter. Surge a cobertura "in loco", em detrimento dos artigos de fundo que dominavam as páginas dos jornais de até então. 


\section{Baudelaire e a modernidade}

Já não era possível chamar a névoa de "fog". No século XIX, a névoa das fábricas havia chegado ao outro lado da Mancha. A cidade de Paris era envolta por uma fuligem espessa, de modo que a existência dos prédios não era mais do que uma sugestão. A Revolução Industrial, iniciada com o pioneirismo britânico no século XVIII, já havia se instalado na França. O capitalismo nascituro promoveu o aparecimento de novos fenômenos dentro de uma inédita estrutura social. Se a literatura de Charles Baudelaire (1821-1867) compreendeu a modernidade, a primeira manifestação do mundo capitalista, na França, ocorreu dentro de uma lógica urbanística.

A crise do sistema urbano se fundou em um processo de dilatações sucessivas da cidade, que ocorreu sem um planejamento prévio. Por conseguinte, a parte central da urbe adensou-se em grandes conglomerados, que se estenderam em conurbações até as áreas mais remotas. Ao mesmo tempo que os centros urbanos se desenvolviam, a falta de um projeto urbanístico deflagrou o surgimento de problemas sociais, como a saturação do tráfego urbano e a falta de infraestrutura habitacional, refletida na proliferação de sobrados e cortiços.

Nesse contexto, a metrópole foi tomada pela multidão, fenômeno central para a compreensão da sociedade parisiense do fim do século XIX. Se, como observado, o modelo medieval da cidade entrou em decadência, as relações de trabalho também modificaram a lógica espacial da urbe. A Revolução Industrial marcou o declínio do sistema doméstico de produção. Na modernidade, os trabalhadores se deslocavam por passagens estreitas e irregulares até 0 mercado de trabalho. À noite, os operários voltavam às casas, fazendo com que a multidão, no processo de exteriorização do trabalho, fosse um fenômeno visível e concreto. (BRESCIANI, 1992 , p. 50).

A pobreza era a mácula da maré humana que trafegava pelas ruas de Paris. À noite, as vielas eram tomadas por escroques e prostitutas, algo corriqueiro em uma sociedade em que a miséria era um espetáculo visível. Se hoje Paris é conhecida pela alcunha de Cidade-luz, à época, a capital francesa era desorganizada, mal iluminada e insalubre.

Dessa forma, o conceito de multidão tornou-se caro aos literatos do século XIX. Além de Baudelaire, outros escritores como Victor Hugo, Émile Zola e Charles Dickens preocuparam-se em retratar a multidão, no momento em que a leitura se espalhava por todas as classes sociais. O próprio público leitor exigia que a literatura passasse a ser um reflexo do espetáculo diário da maré humana nas grandes metrópoles. "Ultrapassando os limites dos ambientes 
privados, da casa familiar, esses autores se colocaram na posição de observadores das cenas de rua. (BRESCIANI, 1992, p.8)

Já no século XVIII, algumas mudanças em Paris foram realizadas. Destaca-se a formação das praças reais, como a Place Royale (denominada de Place de Vosges após a revolução), a Place Louis Le-Grand (hoje, conhecida como Place Vendôme) e a Place Louis XV (atual Place de la Concorde). Data desse período o início da expansão da Avenue des Champs-Elysées e a demolição de casas antigas.

Se a modernidade sepultou a configuração medieval das cidades, a literatura teve de se reorganizar para compreender o capitalismo nascituro. Baudelaire é considerado o pai da poesia moderna. De imediato, seu pioneirismo foi identificado pela nova relação com a cidade de Paris. O poeta inseriu-se na multidão e acompanhou as transformações socioeconômicas finisseculares. Nota-se, entretanto, que o autor de "O Spleen de Paris" não retratava os monumentos que sugiram naquela época, característica central da formação de seu lirismo.

Ainda que sua poesia se desenvolvesse em ambiente citadino, percebe-se um processo de anulação da cidade de Paris. Nesse sentido, Baudelaire não retratava diretamente as novidades das reformas urbanas, mas as "des-realizava", tornando a paisagem uma impressão advinda das "meias-tintas incertas dos crepúsculos". Baudelaire, por conseguinte, abarcou o turbilhão de sensações do homem moderno, em um processo de intensificação da vida urbana que, ao mesmo tempo, forçava um distanciamento ótico e mental do eu lírico.

$\mathrm{Na}$ "cidade anulada", a recusa dos principais monumentos citadinos configura, paradoxalmente, a aderência ao novo modelo de urbe. "Assim, o que poderia num primeiro momento parecer uma fuga ou uma recusa da cidade é antes a negação de um certo olhar sobre ela, a recusa de uma relação mais imediata: a cidade silenciosamente presente nos poemas é um elemento essencial." (VERNIER, 2007, p. 67)

Portanto, a evasão temporal ou espacial, característica da poesia romântica, passa a não ser mais possível em tempos de profundas transformações socioeconômicas. No Romantismo, a floresta intocada era a morada da alma fugitiva do poeta. Na modernidade, nem o tempo da infância consegue aplacar a força do presente. Em Baudelaire, algum grau de consciência havia na documentação da Paris do mundo moderno, como podemos ler em "O cisne", que na publicação original, alicerça-se na homofonia entre "cygne" (cisne) e "sygne" (signo). "La forme d'une ville/Change plus vite hélas, que le coeur mortel". 
Dessa forma, a característica fulcral do eu lírico baudelairiano é a escolha do presente em detrimento do passado, realizando o que o próprio autor chama de "idéalisation forcée": extrair o eterno do transitório. Não à toa, Baudelaire vive em um momento de aceleração da vida urbana, quando os primeiros meios de transporte começam a surgir. Por conseguinte, é no meio da multidão que o poeta encontra sua inspiração. (VERNIER, 2007, p. 64)

Nesse sentido, o olhar é a matéria-prima da poesia de Baudelaire. No final do século XIX, a "literatura panorâmica" estava em voga, gênero literário que serviu de esteio para o poeta. "O escritor que alguma vez desceu ao mercado começa por olhar em volta, como num 'panorama'. Um gênero literário específico faz as suas primeiras tentativas de orientação. É a literatura panorâmica" (BENJAMIN, 2015, p. 37)

Leiamos, pois, um excerto do poema "Perda da auréola":

Meu caro, conheces o meu pavor dos cavalos e das viaturas. Há pouco, ao atravessar o 'boulevard' a toda pressa, e ao saltar na lama através desse caos movimentado onde a morte avança a galope de todos os lados ao mesmo tempo, a minha auréola, num movimento brusco, caiume da cabeça no lodo do macadame. Não tive coragem para a apanhar. Julguei menos desagradável perder as minhas insígnias do que partir os ossos. E, depois, disse comigo mesmo, há males que vêm por bem. Agora posso passear incógnito, fazer más acções, e entregar-me à crápula, como os simples mortais. Eis-me aqui, semelhante a ti, como vês! (BAUDELAIRE, 1991, p. 131)

Sob o aspecto formal, nota-se que o autor é um dos pioneiros na formação de um novo gênero, a poesia em prosa, que floresce em "O Spleen de Paris", cuja primeira edição foi publicada postumamente em 1869. Baudelaire já havia instaurado uma mudança paradigmática ao fazer poético moderno: a adoção do verso livre. De fato, as alterações formais coadunam-se com o esteio pré-simbolista baudelairiano, isto é, a obra literária do autor representa um "détournement" em relação ao Romantismo. No poema, a perda do significante "auréola" simboliza a superação da figura do poeta romântico sacralizado, dotado de mística inspiração e gênio particular. A mudança torna-se fundamental quando as grandes cidades engendram um modo de vida ditado por gestos automáticos e reações instintivas. (BENJAMIN, 2015, p. 197)

Ao enfrentar a cidade moderna, Baudelaire elege o embate eu "versus" multidão como tema central de sua poética. Sua biografia, aliás, nos introduz a uma ambivalência existencial. Oriundo de uma família rica, o poeta conhece a marginalidade simbólica e financeira. Não obstante, sua poesia glorifica a qualidade de "poeta marginal". À época de Baudelaire, já não 
há a segurança da figura arquetípica do herói romântico. "A modernidade é o seu destino fatal. Nela, o herói não está previsto. [...] Pois o herói moderno não é herói - representa papéis de herói". (BENJAMIN, 2015, p. 98)

Dessa forma, infere-se que o eu lírico baudelairiano assume transfigurações, que se relacionam com as figuras heroicas e com a própria biografia do autor. Assim, Baudelaire apresenta-se sob diversas formas, com várias máscaras: dândi, "flâneur" e, até mesmo, trapeiro, no qual o eu lírico se projeta. "Para Baudelaire, o dândi é 'o último vislumbre de heroísmo em tempos de decadência."' (BENJAMIN, 2015, p. 97)

\section{Um olhar brasileiro}

A renovação literária provocada pela obra de Baudelaire foi sedimentada no período histórico em que a França teve maior influência internacional: a belle époque. No fim do século XIX, todos os caminhos levavam a Paris, símbolo do progresso econômico, tecnológico e cultural. Em linhas gerais, entende-se por "belle époque" o período compreendido entre a consolidação da República, em 1789, e o início da Primeira Guerra Mundial, em 1914. A "idade de ouro" seria alcançada com os esforços para a reconstrução da França, após a derrota acachapante na Guerra Franco-Prussiana. Naquele período, mais do que uma retomada financeira, os franceses ansiavam por uma recuperação do moral do país.

É interessante notar, porém, que a expressão belle époque foi cunhada no momento posterior à Primeira Guerra Mundial, quando a França se encontrava em crise econômica inflacionária. Logo, sob uma perspectiva crítica, infere-se que a belle époque foi construída sob as lentes da idealização, inclusive pelo caráter desigual da sociedade francesa do final do século XIX.

Nas ruas de Paris, o desenvolvimento econômico materializava-se em alguns dos referenciais da cultura francesa, que permanecem até hoje no imaginário internacional: cafés, cabarés, salões literários, óperas e alta-costura. Sob a influência do positivismo, o ensino da língua francesa garantiu a assimilação das minorias não-francófonas, fortalecendo o conceito de nação. Era, igualmente, um período de muitos debates. Lembremos de duas leis que estavam em vigor: a lei sobre liberdade de imprensa e de reunião (1881) e a lei sobre o direito a associações (1905).

Por disseminarem a influência francesa a outros países, as exposições universais realizadas em Paris são marcos da belle époque. Nas ocasiões, o país-sede promovia uma representação da 
própria pujança socioeconômica. Em 1889, a exposição ocorreu a partir de um projeto museográfico na região do Champs des Mars, nos Invalides, sendo a Torre Eiffel, à época a mais alta do mundo, símbolo do progresso da engenharia. O projeto de Gustave Eiffel trazia a influência de um novo movimento artístico, o Art Nouveau, que incorporou à arquitetura e às artes decorativas elementos industriais, como a valorização do ferro e vidro, em exuberância decorativa de formas sinuosas.

O Brasil não era indiferente à efervescência cultural parisiense. Ao contrário, quis fazer de sua capital, o Rio de Janeiro, a "Paris Tropical". O Brasil teve a sua própria belle époque, idealizada aos poucos. Em primeiro lugar, a influência francesa no Brasil pode ser percebida na exposição de 1889. No evento, o Brasil vendeu a imagem de "manancial de matérias-primas, de riquezas naturais: café, açúcar, cacau, madeiras, borracha... O Brasil tentava parecer um país atraente para os milhares de europeus que queriam emigrar e tentar a sorte no Novo Mundo". (PINHEIRO \& RODRIGUES, 2012, p. 147)

Decerto, o "lócus"ideal para a implementação da gramática republicana seria a capital, o Rio de Janeiro. As ruas da cidade eram o espaço de mediação entre população e governo, mas, para que a modernidade fosse substantiva, a ordem teria o exemplo francês como referencial. Era preciso, aos moldes do Barão Haussmann, promover reformas urbanas no Rio de Janeiro, fazendo com que o conjunto social e urbanístico da colônia repousasse no passado.

A expansão da cidade se concretizou no eixo norte-sul, com a abertura da Avenida Central (Avenida Rio Branco), que ligava a Praça Mauá até a Praça Floriano Peixoto (Cinelândia). Na praça, foram construídos prédios imponentes ao sabor da época: Theatro Municipal, Museu de Belas-Artes, Câmara Municipal e Supremo Tribunal Federal. A abertura da Avenida Central foi, à época, a obra de maior destaque no contexto das reformas urbanas da cidade, que contavam com o "slogan" "o Rio Civiliza-se!". A avenida era condicionada pelos morros do Castelo e de São Bento. O primeiro seria tido como entrave para a expansão citadina e demolido apenas no início da década de 1920. (PINHEIRO \& RODRIGUES, 212, p. 274)

É importante ressaltar, igualmente, as obras realizadas no porto, dirigidas pelo engenheiro e ministro Lauro Müller. Do porto, as intervenções seguiram até a abertura da Avenida BeiraMar. Lauro Müller também foi o responsável pelo alargamento das ruas, visando o aumento da circulação de ar, pelas obras de saneamento e aperfeiçoamento da iluminação das moradias.

O processo de favelização é sintoma do paradoxo causado pelo positivismo vigente na prefeitura de Pereira Passos. O "Bota-Abaixo", expressão como ficou conhecido o processo de 
reformas urbanas, era de natureza violenta. A desarticulação de sobrados e cortiços intensificou a vulnerabilidade das camadas menos favorecidas da população. Estima-se que, sob a responsabilidade técnica de Paulo de Frontin, foram demolidas cerca de 1.600 residências (a maioria habitações coletivas) ao longo de apenas cinco meses. "Vamos fazer a avenida!", era o mantra das autoridades da época. Não obstante, a violência promovida pelos governantes era de caráter higienista. Era necessário erradicar as doenças que assolavam a pretensa "Paris Tropical": febre amarela, varíola e peste bubônica.

É nesta arena política que jornalismo e literatura são modificados pela modernidade, que, seguindo o exemplo de Baudelaire, foi apreendida por João do Rio em uma nova forma de contar histórias. Nascia a reportagem moderna. Era chegada a hora de ouvir a alma encantadora das ruas.

\section{João do Rio: um baudelairiano}

João do Rio ofereceu-nos a oportunidade de testemunhar a manifestação do "espírito baudelairiano" nos trópicos. Cronista e poeta reagiram de forma similar à modernidade, desvelando os paradoxos do progresso. A suposta civilização que desembarcava na "Paris Tropical" escondia um submundo ainda latente na desigualdade social do Brasil do século XIX. É na atmosfera do decadentismo que João do Rio e Baudelaire se encontram. É imerso na multidão que o cronista descortina as mazelas da cidade, pois, na rua, a República estava em construção, como lemos em "A rua".

A rua é a eterna imagem da ingenuidade. Comete crimes, desvaria à noite, treme com a febre dos delírios, para ela como para as crianças a aurora é sempre formosa [...]. A rua faz celebridades e as revoltas, a rua criou um tipo universal, tipo que vive em cada aspecto urbano [...]. Essas qualidades nós a conhecemos vagamente. Para compreender a psicologia da rua não basta gozar-Ihe as delícias como se goza o calor do sol e o lirismo do luar. É preciso espírito vagabundo, cheio de curiosidades malsãs e os nervos com um perpétuo desejo incompreensível, é preciso ser aqueles que chamamos de flâneur e praticar o mais interessante dos esportes - a arte de flanar. É fatigante o exercício? (RIO, 2013, p. 21)

O excerto da primeira crônica de "A alma encantadora das ruas" reclama uma nova configuração do espaço urbano, em que a rua seria corpo autônomo - personificação elaborada pelo autor - e campo onde diversos tipos sociais entrariam em cena. São eles os personagens de "A alma encantadora das ruas", o que sublinha, na história da crônica, a 
importância dos arquétipos da cidade. Divididas em cinco partes, as crônicas do livro levam nomes de tipos sociais, normalmente associados às camadas mais pobres da sociedade, entre elas: "Os tatuadores", "As mulheres mendigas", "Os trabalhadores da estiva".

"A rua" desperta a ambiguidade da "flânerie" que em João do Rio seria reforçada. Ao mesmo tempo que a prática pressupõe certa ociosidade, o cronista é um ser atento ao jogo que se revela nas ruas. Na obra, o autor percorre ambientes marginalizados da cidade que ganhava ares parisienses. Em "Visões d'ópio", descreve o vício que condenava os "chins".

Há uma vasta sala estreita e comprida, inteiramente em treva. A atmosfera pesada, oleosa, quase sufoca. [...] A custo nossos olhos acostumam-se à escuridão, acompanham a candelária de luzes até o fim, até uma alta parede encardida, e descobrem em cada mesa um cachimbo grande e um corpo amarelo, nu da cintura para cima, corpo que se levanta assustado, contorcionando os braços moles. Há chins magros, chins gordos, de cabelo branco, de caras despeladas [...]. O ambiente tem um cheiro inenarrável, os corpos movem-se como larvas de um pesadelo. (RIO, 2013, p. 94)

Em um primeiro momento, João do Rio preocupa-se em caracterizar o " $\mathrm{n} 019$ do Beco dos Ferreiros", lugar insalubre, mal iluminado, espaço destinado às franjas excluídas da cidade moderna. Na descrição, é curioso notar seus procedimentos. O ambiente é descrito como em uma pintura: "atmosfera pesada oleosa", "candelária de luzes até o fim", "alta parede encardida". Existe, pois, a necessidade de transmitir a experiência de estar entre os "comedores de ópio". Por conseguinte, João do Rio adota sinestesias para a configuração da atmosfera. Ao dizer que "o ambiente tem um cheiro inenarrável", o autor explicita o caráter investigativo de sua "flânerie", ao mesmo tempo que confessa estar embriagado por um mar de sensações.

A visita de João do Rio ao prédio onde se consumia ópio denota um interesse tipicamente moderno, na medida em que a artificialidade passava a reger as relações sociais. Deve o indivíduo moderno fabricar-se em um processo de estetização de si. Os avanços na indústria de cosméticos são resultado do impulso do indivíduo da cidade moderna à diferenciação. $O$ avanço do consumo de drogas é consequência negativa dos novos artifícios da modernidade. Em "O poema do haxixe"(1860), Baudelaire já previra os efeitos da dependência química. No fim do século XIX, o homem moderno embriagou-se no mundo das drogas como em uma alucinação coletiva. O poeta revelou o submundo descrito por João do Rio.

Essa acuidade de pensamento, esse entusiasmo dos sentidos e do espírito, devem ter aparecido ao homem, em todos os tempos, como o 
primeiro dos bens; por isso, considerando apenas a volúpia imediata, ele, sem se inquietar por violar as leis da sua constituição, procurou na ciência física, na farmacologia, nas bebidas mais grosseiras, nos perfumes mais sutis, sob todos os climas e em todos os tempos, os meios de fugir, ainda que por algumas horas apenas, de seu habitáculo de lama e, como diz o autor de Lazare, 'arrebatar o paraíso de um só golpe". Ai! Os vícios do homem, por mais cheios de horror que suponhamos contêm a prova (não fosse por sua infinita expansão!) do gosto dele pelo infinito [...]. (BAUDELAIRE, 2003, p. 17)

A artificialidade do mundo moderno implica a fabricação do homem. Nesse sentido, João do Rio adota as duas principais transfigurações que Walter Benjamin identificou em Baudelaire. $O$ cabelo gomalinado, o monóculo e o colarinho "verdeau" denunciam que João do Rio era, afinal, também um dândi.

\section{Alma de repórter}

A publicação de "A alma encantadora das ruas" sintetizou as características centrais da obra de João do Rio. Documento precioso do Rio de Janeiro do início do século XX, o livro demonstra que o autor foi sintoma e agente da modernização da imprensa brasileira.

A "Alma encantadora das ruas" é delimitada por um preâmbulo e um posfácio - "A rua" e "A musa das ruas", respectivamente - oriundos de conferências proferidas pelo autor. Nesse sentido, podemos delimitar o campo etnográfico da obra literária. João do Rio descobre que "a rua é um fator de vida das cidades", destacando a primazia do público em detrimento da esfera privada. Interessante notar que, ao contrário da tradição poética, as musas são "invocadas" pelo escritor ao término de sua investigação. João do Rio deixa implícita a necessidade de se estar na rua para, então, na vivência da cidade moderna, inspirar-se. "A musa das ruas é a musa que viceja nos becos e rebenta nas praças, entre o barulho da populaça e a ânsia de todas as nevroses, é a musa igualitária, a musa-povo". (RIO, 2013, p. 2019)

Pioneiro na constituição da reportagem moderna, João do Rio incorpora técnicas específicas na escrita de suas crônicas. Dessa forma, transmite ao conteúdo apresentado em "A alma encantadora das ruas" um problema - ou solução - de gênero textual. O leitor depara-se com um hibridismo estilístico, que combina a objetividade do repórter ao lirismo do cronista. Observamos, portanto, o surgimento da crônica-reportagem. Leiamos um trecho de "Os tatuadores": 
Enquanto andou a fornecer-me o seu profundo saber, Madruga teve três dessas senhoras - a Jandira, a Josefa e a Maria. A primeira a figurar debaixo de um coração foi a Jandira. Um belo dia a Jandira desaparecia, dando lugar a Josefa, que triunfava em cima, entre as chamas. Um mês depois a letra J sumira-se e um $M$ dominava no meio do coração. Os marcadores têm uma tabela especial, o preço fixo do trabalho. As cinco chagas custam $1 \$ 000$, uma rosa $2 \$ 000$, o signo de Salomão, o mais comum e menos compreendido porque nem um só dos que interroguei o soube explicar, $3 \$ 000$, as armas da Monarquia e da República $6 \$$ a $8 \$$, e há Cristos para todos os preços. (RIO, 2013, p. 54)

João do Rio seleciona Madruga como personagem central para a sua crônica. Os sucessivos casamentos ocasionam as várias alterações na tatuagem. O repórter descobre, nesse momento, o insólito e o pitoresco, características do texto noticioso. Em seguida, deixa evidente seu trabalho de pesquisa, o qual, hoje, conhecemos pelo nome de "apuração". Madruga é sua fonte, ele pode fornecer "o seu profundo saber", que se revela nos detalhes apreendidos pelo repórter. O trabalho de apuração é nítido no levantamento de dados presentes na "tabela especial". O apego aos detalhes se contrapõe à faceta lírica de João do Rio, dessa vez obumbrada pela função informativa da crônica.

A natureza criativa de João do Rio não pode ser dissociada da condição do indivíduo na modernidade. Assim, se Baudelaire foi o pintor da vida moderna, João do Rio foi perito. A criação de ambos os autores privilegia a estética (ciência da percepção), visto que é moldada por uma "arqueologia dos sentidos".

É a partir dessa concepção socialmente implicada do corpo que se torna possível uma leitura da obra de João do Rio orientada pela busca das expressões sensoriais. Suas muitas crônicas dedicadas à listagem das novidades da cultura material e aos usos dados pelos cariocas a esses aparatos da experimentação urbana são, nesse sentido, muito mais que o sinal da mundanidade do autor. [...] Os sentidos como meio de expressão da introjeção de estímulos são, portanto, pistas nessa leitura sensorialmente orientada da etnografia de João do Rio. (O'DONNELL, 2013, p. 144)

$\mathrm{Na}$ modernidade, repórter e poeta estão atados à imanência, embriagados pelo mundo sensível das grandes metrópoles. A criação jornalística ou literária nasce dos cinco sentidos visão, tato, olfato, paladar e audição -, porque deles a paisagem será extraída. Dessa forma, o sentido da visão tem primazia, porque é a "via principal de acesso ao universo relacional que 
cerca o indivíduo". Baudelaire deixou, para João do Rio, a herança do olhar: a consciência de que a criação literária nasceria de um "ver-para-crer".

João do Rio e Baudelaire fazem da "arqueologia dos sentidos" matéria-prima para a criação literária. A obra do poeta francês não abandona por completo o olhar viciado por certo egocentrismo romântico. Mesmo adotando a postura "adandinada", João do Rio dá um passo adiante na modernidade, pois sua crônica-reportagem se inaugura no seio da população marginalizada, voz ativa em "A alma encantadora das ruas".

Os narradores de seus contos contracenam com personagens de aventura quase passivos, pervertidos, presos, como leitor, nas malhas discursivas, seduzidos pelo desejo do discurso, todos "ardendo" - como fala o narrador - por ouvir sua história monstruosa ou estranha. [...] João do Rio dissolve pelo reverso - agora falando também em termos da série literária sua contemporânea - o discurso unicamente laudatório do progresso. Seu texto destoa, com sua modernização estilística e temática, do tom vitorioso e estreitamente nacionalista de um Coelho Neto ou de um Bilac, por exemplo, que acriticamente apenas louvam modernidade imposta em nome da higiene e do bom gosto. (CURY, 1996, p. 53)

A crônica, gênero essencialmente urbano, capta fragmentos na fugacidade da cidade moderna. A aceleração da vida cotidiana reflete-se no compartilhamento de histórias públicas, que surgem nas ruas do Rio. A fragmentação condiciona a vivência moderna a tal ponto que se liga ao aparecimento de inúmeros empregos informais, tema de "Pequenas profissões".

O Rio tem também suas pequenas profissões exóticas, produto da miséria ligada às fábricas importantes, aos adelos, ao baixo comércio; o Rio, como todas as grandes cidades, esmiúça no próprio monturo a vida dos desgraçados. Aquelas calças de cigano, deram-Ihas ou apanhou-as ele no monturo, mas como o cigano não faz outra cousa na vida senão vender calças velhas e anéis de plaquet, aí tens tu uma profissão da miséria, ou se quiseres, da malandrice - que é sempre a pior das misérias. (RIO, 2013, p. 44)

O proletariado torna-se, dessa forma, símbolo do submundo carioca. Com os trabalhadores, João do Rio identifica o que há de novo na cidade, isto é, revela notícias para o público leitor da época. Em "As mariposas do luxo", João do Rio acompanha o fim da jornada de trabalho de um grupo de operárias, que se depara com as vitrines de produtos importados.

Elas, coitaditas! Passam todos os dias a essa hora indecisa, parecem sempre pássaros assustados, tontos de luxo, inebriados de olhar. Que 
Ihes destina no seu mistério a vida cruel? Trabalho, trabalho; a perdição, que é a mais fácil das hipóteses; a tuberculose ou o alquebramento numa ninhada de filhos. Aquela rua não as conhecerá jamais. Aquele luxo será sempre a sua quimera. (RIO, 2013, p. 140)

Está implícita, no trecho acima, a ambiguidade mobilidade "versus" imobilidade. Para as operárias, é pouco provável uma mudança social, senão um possível descenso. Decerto, estão imóveis olhando as vitrines com produtos que jamais poderão comprar. Ao mesmo tempo, as trabalhadoras logo se encaminharão às suas casas, enquanto muitos olhos passam nos bondes da "Paris Tropical".

Os olhos do repórter João do Rio diagnosticam a desigualdade social que permaneceria presente por mais um século no Brasil. O jornalista herda do poeta Baudelaire a capacidade de documentar o mundo fragmentado em contingências.

\section{Considerações finais}

O presente estudo deixa inequívoca a influência de Baudelaire em João do Rio. Se a comparação parece impertinente devido à distância espaço-temporal, o cronista e repórter João do Rio mostrou-se ciente do legado do projeto poético baudelairiano. A crônica, que no nome estabelece uma ligação com o tempo útil, apenas reforça a natureza efêmera do cotidiano de choques e reações instintivas, mediados pelos encontrões na multidão.

Na modernidade, a imprensa terá novo papel de mediador, ordenando os signos linguísticos da esfera pública. Nesse sentido, a belle époque brasileira pode ser considerada símbolo das transformações proporcionadas pela grande imprensa. As novas tecnologias aumentaram o público leitor, ao mesmo tempo que novos gêneros jornalísticos surgiram para atender à demanda perene de qualquer sociedade: ter o jornal como próprio espelho.

Na disputa de narrativas sobre a República, João do Rio atuou como agente transformador do jornalismo, sendo pioneiro no exercício da reportagem moderna. É interessante notar que, à época, literatura e jornalismo ainda ocupavam o mesmo espaço, de modo que a "Alma encantadora das ruas" é sintoma do hibridismo entre crônica, na condição de gênero literário, e reportagem, o carro-chefe da imprensa moderna.

A apuração factual de João do Rio não pode ser desvinculada de sua pesquisa empírica, baseada na "arqueologia dos sentidos", que Baudelaire experimentara nos paraísos artificiais. 
A sinestesia típica do simbolismo francês triunfa na criação literária inspirada pelo olhar, em um constante "ver-para-crer".

João do Rio atinge a alma das ruas, na medida em que Baudelaire deixa escapar a aura do poeta romântico, incorporando transfigurações decadentistas em versos fatalistas, que cedem às profundas sensações das metrópoles. Dândi e "flâneur", transfigurações caras aos autores, são, dessa forma, resultado de um heroísmo decadentista. Enquanto o autor de "As flores do mal" vislumbra a modernidade na poesia lírica, não abdicando totalmente do egocentrismo romântico, João do Rio é testemunha ocular da ruína da população marginalizada pelas reformas urbanas, que ambicionavam transformar a capital brasileira em uma "Paris Tropical". Herdeiro do olhar baudelairiano, João do Rio, o repórter, foi a campo apurar a matéria-prima de seu trabalho: a notícia.

\section{Referências bibliográficas}

BAUDELAIRE, Charles. As Flores do Mal. Lisboa: Relógio D 'Água, 2003.

BAUDELAIRE, Charles. Le Spleen de Paris: Petits poèmes en prose. Paris: Gallimard, 2006. BAUDELAIRE, Charles. Paraísos Artificiais. São Paulo: L\&PM, 1998.

BENJAMIN, Walter. Baudelaire e a modernidade. São Paulo: Autêntica, 2019.

BORGES, Rogério, JORGE, Thais. Dilema e experimentação em João do Rio: contribuições ao jornalismo e à literatura. Contracampo, Rio de Janeiro, n. 18, junho. 2008.

BRESCIANI, Maria Stella. Londres e Paris no século XIX: o espetáculo da pobreza. São Paulo, Brasiliense, 1992.

CURY, Maria. O avesso do cartão-postal - João do Rio perambula pela capital da República. Literatura e Sociedade, v.1, n.1. 2006.

FERREIRA, Raul. No jardim do mal: Baudelaire no Brasil. A Cor das Letras, Feira de Santana, n. 8, 2007.

HARVEY, David. Paris, capital da modernidade. São Paulo, Boitempo, 2015.

MACHADO, Nara, PONGE, Robert. As transformações urbanísticas de Paris no século XIX: análise e reflexões. Revista XIX, Brasília, n.1, junho. 2014.

MATTOS, Betty, Travassos, Alda. Colombo 100 anos: no dia-a-dia da cidade do Rio de Janeiro. Rio de Janeiro, Betty Mattos, 1994.

MATOSINHOS, Lucas. Décadence avec Élégance: Dandismo Heróico de Charles Baudelaire (1846-1867). Dissertação (Mestrado em História). Universidade Federal de Minas Gerais, Minas Gerais, 2009. 
MEIRELLES, Ricardo. Baudelaire no Brasil: Traduções. ABRALIC. 2020. Disponível em:

https://abralic.org.br/eventos/cong2008/AnaisOnline/simposios/pdf/063/RICARDO MEIRELLES . .pdf

O'DONNELL, Julia. De olho na rua: A cidade de João do Rio. Rio de Janeiro, Zahar, 2008. PINHEIRO, Luís, RODRIGUES, Maria (org.). A Belle Époque brasileira. Lisboa, LuSofia, 2012. RODRIGUES, Antonio. João do Rio: A cidade e o poeta, O olhar de flâneur na Belle Époque tropical, 2000.

SIMMEL, Georg. As grandes cidades e a vida do espírito (1903). Mana, Rio de Janeiro, v. 11, n. 2, p. 577-591, Oct. 2005 .

SIQUEIRA, Denise. João do Rio, repórter da pobreza na cidade. Em questão, Rio de Janeiro, v.10, n.1, p. 81-93, jan-jun. 2004.

VERNIER, France. Cidade e modernidade nas "Flores do Mal" de Baudelaire. São Paulo: ARS. V. 5. N. 10, 2007. 